\title{
A UTILIZAÇÃO DOS RECURSOS TECNOLÓGICOS COMO FERRAMENTA DE AUXÍLIO NO ENSINO DE QUÍMICA
}

\author{
Damião Alves dos Santos Silva, Universidade Federal de Campina Grande (UFCG), \\ damalvescz@hotmail.com \\ Orientador, Luciano Leal de Morais Sales, Universidade Federal de Campina \\ Grande (UFCG), \\ luciano_sales@hotmail.com
}

\begin{abstract}
RESUMO
A utilização de recursos tecnológicos na sala de aula tem sido discutida constantemente, visto que as ferramentas tecnológicas se apresentam como um novo método de auxilio no ensino, o uso das tais se faz necessário no âmbito escolar. A utilização das mesmas proporciona aos alunos uma maior compreensão dos conteúdos de química de modo que minimizam suas dificuldades. Está pesquisa propõe a utilização de recursos tecnológicos como, por exemplo, o uso de softwares educacionais no auxílio do ensino de química. Observando que existe a falta de apoio didático durante as aulas ministradas pelo professor, o uso de tais ferramentas favorece novas formas no processo de ensino-aprendizagem.
\end{abstract}

PALAVRAS-CHAVE: Tecnologia; Ensino; Química.

\begin{abstract}
The use of technological resources in the classroom has been constantly discussed, since the technological tools are presented as a new method of teaching aid, the use of such is necessary in the school context. Their use provides students with a greater understanding of chemistry content so as to minimize their difficulties. This research proposes the use of technological resources such as the use of educational software to aid the teaching of chemistry. Noting that there is a lack of didactic support during the classes taught by the teacher, the use of such tools favors new forms in the teaching-learning process.
\end{abstract}

KEY - WORDS: Technology; Teaching; Chemistry.

\section{RESUMEN}

La utilización de recursos tecnológicos en el aula ha sido discutida constantemente, ya que las herramientas tecnológicas se presentan como un nuevo método de auxilio en la enseñanza, el uso de las tales se hace necesario en el ámbito escolar. La utilización de las mismas proporciona a los alumnos una mayor comprensión de los contenidos de química de modo que minimizan sus dificultades. Esta investigación propone la utilización de recursos tecnológicos como, por ejemplo, el uso de software educativo en el auxilio de la enseñanza de química. Observando que existe la falta de apoyo didáctico durante las clases impartidas por el 
profesor, el uso de tales herramientas favorece nuevas formas en el proceso de enseñanzaaprendizaje.

PALABRAS - CLAVE: Tecnología; Enseñanza; Química.

\section{INTRODUCÃO}

A tecnologia vem sendo utilizada como uma ferramenta de apoio no ensino básico, a maioria das escolas já dispõem de laboratórios de informática, salas equipadas com equipamentos de áudio e vídeo.Os computadores são um dos principais recursos tecnológicos utilizados para auxiliar o professor durante as aulas, como também desperta nos alunos um maior interesse e gera uma maior participação nas aulas.

O computador é uma máquina muito complexa que permite realizamos inúmeras funções, além de ser utilizado para navegar na internet, onde temos acessos aos mais diversos tipos de sites que podem ser utilizados como suporte na compreensão dos assuntos de química abordados em sala de aula, de acordo com SANTOS (2010, P.10) "as ferramentas computacionais possuem um grande potencial para auxiliar tanto o professor quanto o aluno no processo ensino-aprendizagem de química."

Na disciplina de química alguns conteúdos trazem conceitos que apenas a utilização do quadro ou as explicações do professor são insuficientes para o total entendimento por parte dos alunos, daí onde se faz necessário o uso dos recursos tecnológicos como os softwares educacionais, plataformas digitais, laboratórios virtuais, jogos online, entre outros.

Muitas escolas públicas não possuem laboratórios de química onde o professor possa usá-lo para demonstrar como os fenômenos químicos que estão sendo discutidos em sala de aula ocorrem, diante disso o uso das ferramentas tecnológicas é visto como um meio alternativo para suprir essa necessidade.

\section{UTILIZAÇÃO DE SOFTWARES NO ENSINO DE QUÍMICA}

É evidente a evolução dos âmbitos sociais, de modo que o ambiente escolar não se distanciou disso e seguiu as transformações da sociedade como também os avanços tecnológicos. De acordo com GRISPUN (2001) a escola sendo um espaço que pretende exercer o desenvolvimento das capacidades físicas, intelectuais e morais dos alunos, deve 
assumir o papel de democratização dos saberes e reconhecer a necessidade de se trazer a tecnologia para dentro de seus muros não somente para ser utilizada, mas também para ser entendida, criticada e construída, ou seja, o ensino escolar na perspectiva de uma educação tecnológica deve assumir "um comprometimento com a tecnologia".

É importante destacar que o professor não possui apenas a função de ensinar, mas criar condições que possam facilitar a aprendizagem, utilizando os recursos didáticos que a escola possui e buscar outros meios que o auxilie.

É preciso lembrar que os computadores são ferramentas como quaisquer outras. Uma ferramenta, sozinha, não faz o trabalho. É preciso um profissional, um mestre no ofício, que a manuseie, que a faça fazer o que ele acha que é preciso fazer. É preciso, antes da escolha da ferramenta, um desejo, uma intenção, uma opção. Havendo isto, até a mais humilde sucata pode transformar-se em poderosa ferramenta didática. Assim como o mais moderno dos computadores ligado à Internet. Não havendo, é este que vira sucata (FONSECA. 2001 p.2).

Para AZEVEDO (2007) o uso do computador na educação consistiria simplesmente na informatização dos meios tradicionais de instrução, podendo enriquecer ambientes de aprendizagem onde o aluno, interagindo com os objetos desse ambiente, tem a chance de construir o seu conhecimento baseado em recursos antes não oferecidos, mas muito mais atrativos ou motivadores.

De acordo com BONA (2009) a química por ser uma disciplina de contexto eminentemente experimental, também apresenta conteúdos abstratos e de difícil compreensão, visualização principalmente pelos alunos. Como solução para esse problema o uso de recursos tecnológicos, como por exemplo, softwares educacionais para visualizar moléculas em três dimensões, jogos educativos online que abordam as temáticas ambientais, laboratórios virtuais que simulam experimentos que envolvem reações químicas. Com isso as ferramentas tecnológicas, proporcionam uma nova fonte metodológica que contribui significativamente para o melhoramento do ensino, superando as dificuldades encontradas nas escolas.

Os softwares oferecem a possibilidade de o aluno desenvolver hipóteses, testá-las, analisar os resultados, eaprimorar os conceitos. Como ressalta RAUPP et tal(2009), dentre as ferramentas tecnológicas, os softwares de visualização e construção de modelos tem ajudado os alunos de maneira efetiva, tal como pesquisas na área de educação em química tem mostrado, pois apresentam múltiplas representações, fazem uma conexão com o nível 
macroscópico, possibilitam a transformações de representação bidimensionais em tridimensionais e usam informações explicitas.

\section{METODOLOGIA}

Foram analisados vários artigos onde realizou-se um levantamento com relação à utilização de recursos tecnológicos mais especificamente a temática sobre o uso de softwares no ensino de química, com o intuito de buscar relatos de experiências que abrangem os diversos conteúdos químicos, que de alguma forma possam ajudar na compreensão teórica, e baseados nessa perspectiva estão sendo desenvolvidas múltiplas atividades com 25 alunos de uma escola pública no município de Cajazeiras - PB.

Os alunos que estão participando das atividades foram questionados a respeito da utilização das ferramentas tecnológicas, onde opinaram a respeito da mesma. Algumas atividades como a apresentações de textos e posteriores discussões sobre a utilização e contribuições que os softwares trazem para o ensino de química já foram desenvolvidas, e outras atividades então sendo planejadas e desenvolvidas com o intuito de melhorar a concepção dos alunos em relação aos fenômenos químicos que estão sendo abordados em sala de aula, a exemplo da visualização dos modelos tridimensionais das moléculas dos compostos orgânicos. É importante destacar que todos os softwares são gratuitos e possuem versão no sistema operacional Linux.

A proposta inovadora que utiliza softwares educacionais como também outros tipos de recursos tecnológicos estão sendo desenvolvidos na turma do $3^{\circ}$ ano A da Escola Estadual de Ensino Médio Cristiano Cartaxo na cidade de Cajazeiras - PB através do Programa Institucional de Bolsa de Iniciação à docência - PIBID subprojeto Química. Essa proposta foi desenvolvida a partir das dificuldades dos alunos em visualizarem alguns fenômenos químicos que são essenciais para a compreensão da disciplina.

\section{DESCRIÇÕES E RESULTADOS}

A realização da pesquisa a respeito do uso das fontes tecnológicas no auxílio do ensino de química surgiu a partir da observação que ocorreu durante as aulas ministradas pelo professor, onde os alunos apresentaram grande dificuldade principalmente no entendimento 
relacionado aos modelos tridimensionais das moléculas dos compostos orgânicos. Diante de uma análise crítica mediante as formas de utilização dos recursos tecnológicos no ensino de química, algumas ações foram feitas no intuito de obter resultados satisfatórios mediante a utilização dos softwares educacionais. Questionando a opinião dos alunos em ralação a contribuição dos softwares para o aprendizado dos conteúdos de química que são abordados na terceira série do ensino médio, o gráfico 1 a seguir destaca:

GRÁFICO 1:De que maneira os softwares podem influencia no aprendizado de química:

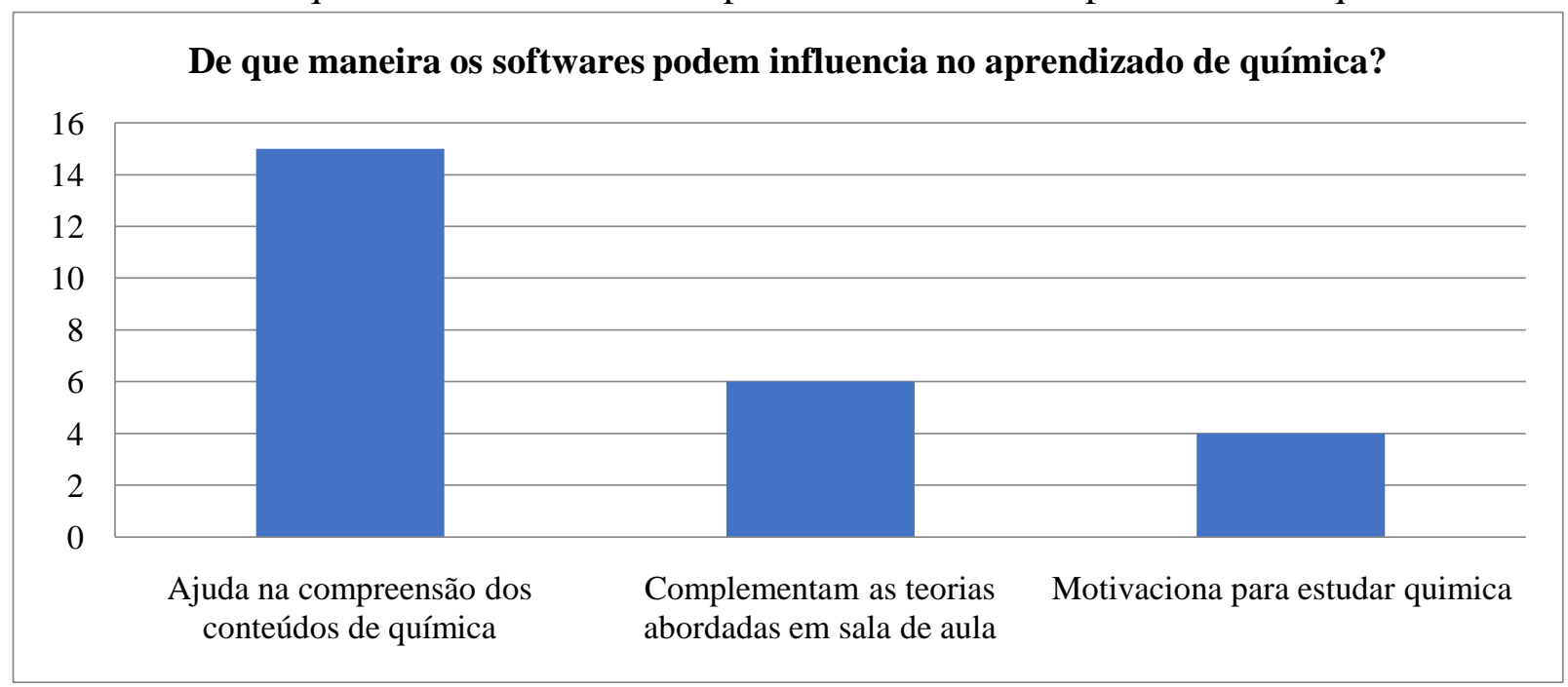

Fonte: própria (2017)

Dos 25 alunos que responderam a pergunta "De que maneira os softwares podem influencia no aprendizado de química?", 15 disseram que ajudam na compreensão dos conteúdos de química, 6 deles afirmarão que complementam as teorias abordadas em sala de aula pelo professor, e 4 responderam que os softwares motivacionam para estudarem química. Essa situação pode ser justificada pelo fato de que os alunos consideram a disciplina de química de difícil compreensão, e o uso de ferramentas tecnológicas proporciona uma maneira de assimilar os conteúdos.

GRÁFICO 2: Opinião dos alunos em relação a contribuição dos softwares para o aprendizado de química. 


\section{Opinião dos alunos em relação a contribuição dos software para o aprendizado de química}

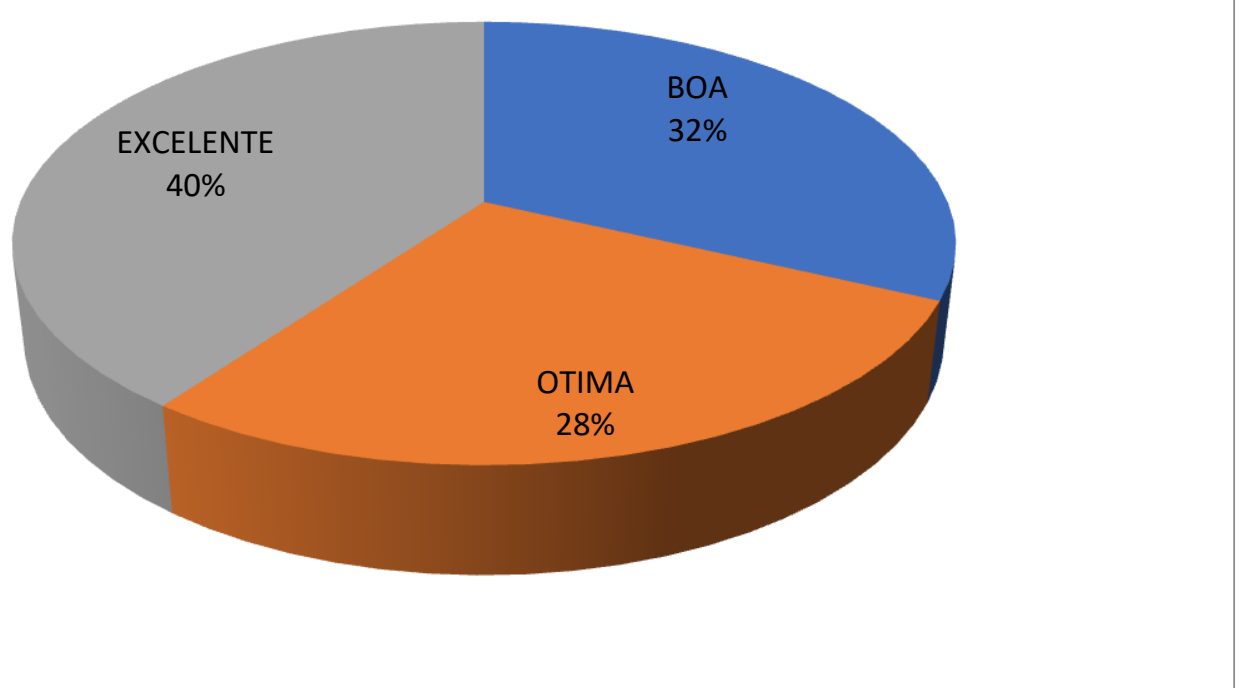

Fonte: própria (2017)

O gráfico 2 apresenta a opinião dos alunos sobre a influência dossoftwares no seu aprendizado

Diante dos dados acima apresentados podemos afirmar baseados na opinião dos alunos a maneira de como os softwares educacionais contribui significativamente para o aprendizado dos alunos. Dessa maneira se faz necessário a inserção dos recursos tecnológicos no âmbito escolar.

O uso da tecnologia no ensino deve ocorrer demaneiraque facilite e contribua para um melhoramento do aluno em relação aos objetivos educacionais, com isso tais tecnologias devem apresentar linguagem de fácil entendimento e não apresentem grandes dificuldades na sua utilização, assimSegundo (SANTOSet tal, 2009), o software educacional deve contribuir para que o aluno alcance o objetivo educacional e para isso deve ser amigável e de fácil utilização, possuindo aspectos motivacionais e respeitando individualidades.

\section{CONSIDERAÇÕES FINAIS}

Está pesquisa foi desenvolvida com intuito de propor novos métodos pedagógicos que utiliza os recursos tecnológicos como ferramenta de auxílio para o ensino de química na educação básica. A partir das dificuldades demonstradas pelos alunos fez-se necessário a buscar por meios alternativos que contribuíssem no entendimento dos conteúdos relacionados 
à química orgânica. Buscou através de revisões bibliográficas relatos que confirmam que o uso da tecnologia a exemplo dos softwares educacionais é de grande relevância para uma maior compreensão dos conteúdos abordados em sala de aula.

\section{REFERÊNCIAS}

AZEVEDO, BRENO FABRÍCIO TERRA. Tópicos em Construção de Software Educacional. Disponível em<http://www.inf.ufes.br/ tavares/trab3.html>. Acesso em: 15 jul. 2017.

BONA, B. O. Análise de softwares educativos para o ensino de matemática nos anos iniciaisdo ensino fundamental. Experiências em Ensino de Ciências, vol.4, n. 1, pp.35-55, 2009.

FONSECA, Lúcio. Tecnologia na Escola. 2001. Disponível em <http://www.aescola.com.br/aescola/seções/20tecnologia/2001/04/0002>. Em Acesso em: 04 jul. 2017.

GRISPUN, M. P. S. (org). Educação tecnológica: desafios eperspectivas. 2a ed. São Paulo:Cortez, 2001.

RAUPP, Daniele; SERRANO, Agostinho; MOREIRA, Marco Antonio. Desenvolvendo habilidades visuoespaciais: uso de software de construção de modelos moleculares no ensino de isomeria geométrica em química.Experiências em ensino de ciências, v. 4, n. 1, p. 65-78, 2009.

SANTOS, D.O. et al. Softwares educativos livres para o Ensino de Química: Análise eCategorização. In: XV Encontro Nacional de Ensino de Química (XV ENEQ). Brasília DF, julho,2010. Disponível em: <http://www.Xveneq2010.unb.br/>. Acesso em: 20 jul. 2017.

SANTOS, R.E.S.; MAGALHÃES, C.V.C; SOBREIRA, A.C. S;BEZERRA, C.A; SOUZA, E.P. R. .O Uso do SoftwareEducacional como uma estratégia para auxiliar alunos comdificuldades de aprendizagem. In: Io Encontro Regional deTecnologia e Negócios, UFRPE/UAST. 2009. 